\title{
A OPÇÃO PARLAMENTARISTA PARA A AMÉRICA LATINA*
}

ARTURO VALENZUELA**

Historiadores do futuro caracterizarão, sem dúvida, a última década do século XX como a década da revolução democrática. Aconteceram mudanças profundas não somente no Leste da Europa mas também em outras partes do mundo. Em nossa América, pela primeira vez em sua história todos os países da América do Sul são liderados por presidentes eleitos em votações competitivas e relativamente livres.

A grande incógnita, entretanto, é se essa revolução será durável, ou se chegarão novamente ondas de autoritarismo. Por isso o tema da "governabilidade na democracia" é de suma importância. Tanto a América Latina como também os países do Leste europeu estão frente ao grande desafio de como compatibilizar a convivência democrática e a construção de uma sociedade melhor com processos de reforma estrutural do estado e do mundo econômico. Os temas são muitos. No Centro de Estudos Latino-Americanos da Universidade de Georgetown, que presido, começamos um projeto bastante ambicioso de pesquisa, em colaboração com especialistas de sete países latino-americanos.

\footnotetext{
-Uma versão preliminar deste artigo foi apresentada no seminário "Parlamentarismo e Sistema Eleitoral", promovido pelo Senado Federal do Brasil em junho de 1991.

* Tradução de Letizio Mariconda e Pablo Rubén Mariconda.
} 
O projeto abrange distintas problemáticas, a partir dos mecanismos para garantir a estabilidade macroeconômica com crescimento e distribuição até a privatização, a descentralização e a maior participação da cidadania no trabalho nacional.

Mas o tema que mais nos diz respeito e que é a preocupação fundamental do meu próprio trabalho, é o das instituições democráticas como tais. Esse trabalho resume-se numa pergunta muito concreta. Os países democráticos com instituições políticas do tipo parlamentar são mais estáveis e mais aptos a resolver os problemas de governabilidade que os países com instituições do tipo presidencial? E se não for possível responder de forma categórica à pergunta por não existir uma resposta simples que abarque todos os casos, podem identificar-se condições pelas quais um sistema parlamentar seria mais apropriado que um sistema presidencial, ou vice-versa? Meu próprio trabalho, baseado especificamente sobre c caso do Chile, levou-me à conclușão de que uma bọa parte dos problemas da democracia chilena podem atribuir-se à rigidez do sistema presidencial idealizado pelos norte-americanos ao înal do século XVIII.

No meu entendimento, a falta de coerência entre as tradições políticas ou a idiossincrasia pclítica do chileno e o sistema institucional copiado dos artífices da nação norte-americana é uma das causas fundamentais da permanente crise política do Chile. Nos termos de Lijphart, o Chile e outros países latino-americanos, por serem sociedades divididas, precisam de sistemas políticos aptos a estruturar consensos e maiorias governamentais.

Acredito ser este o ponto medular. Nos países com sistemas de partidos políticos competitivos e polarizados, com grandes divergências políticas, sociais e econômicas que por definição impossibilitam a estruturação de governos ccm maioria política, o sistema de governo parlamentar é múito mais apto que o presidencial. Nas sociedades fragmentadas onde não se podem obter maiorias estáveis o sistema parlamentar tende à construção de coalizões de governo, e não à atomização política.

Ao refletir mais amplamente sobre o tema, conjuntamente com outros colegas como o espanhol Juan Linz, da Universidade de Yale, constatamos que existe um padrão bastante dramático: a grande maioria das democracias estáveis do mundo contemporâneo são regimes parlamentares.

Contudo, nos países muito divididos, ccmo a Índia, Itália, Israel, e vários países do Caribe, os regimes parlamentares ex- 
perimentam graves críses periódicas de governo, porém não necessariamente de regime. Os governos podem cair freqüentemente, mas não o sistema democrático como tal. O estudo comparativo nos mostra que a única democracia do tipo presidencial que se conservou durante várias gerações sem uma ruptura institucional é norte-americana.

A Finlândia e a França são casos híbridos, e o veredicto sobre a estabilidade do sistema francês ainda não pode ser formulado, posto que esse país teve somente três anos de governo de "coabitação" - e o exemplo enormente negativo do semipresidencialismo da República de Weimar nos deveria fazer refletir sobre essa opção institucional. As repúblicas presidenciais do século XIX na Europa, como aquelas da França e da Romênia, duraram muito pouco. Somente o Chile, entre as democracias restritas da América Latina, teve certo êxito em consolidar um sistema relativamente estável - um sistema porém onde as crises ocasionais terminaram numa profunda crise do sistema, com uma guerra civil no final do século XIX e um golpe de Estado oitenta anos mais tarde.

Se excluímos da nossa amostragem as democracias do mundo desenvolvido, que em sua grande maioria são sistemas parlamentares, pode-se apreciar que a fórmula de um primeiro ministro escolhido por um parlamento também teve maior êxito no terceiro mundo. O estudo de Fred Riggs sobre setenta países do terceiro mundo mostra que os 30 países com regimes presidenciais tinham experimentado uma ruptura do sistema institucional pelo menos uma vez - e muitos tinham experimentado várias quebras. Ao contrário, em 40 regimes parlamentares, somente $30 \%$ tinham experimentado uma quebra do sistema. É evidente que existem regimes parlamentares que fracassaram redondamente, como demonstram os casos africanos e do Oriente Médio, países divididos por conflitos étnicos, nos quais os sistemas parlamentares têm mesmo acelerado o colapso institucional. Estamos perfeitamente conscientes de que a existência de crises sociais muito fortes podem produzir quebras institucionais em qualquer sistema político.

Quase todos os especialistas concordam que o sistema presidencial teve êxito somente num país - o país maximamente identificado com o sistema de separação de poderes, ou de dupla soberania, como o chama Juan Linz, país que idealiza a fórmula da democracia presidencial. Refiro-me aos Estados Unidos da 
América. O caso dos EUA é importante para nossas reflexões teóricas sobre o tema, porque é um caso que se afasta da norma - e como tal pode dar-nos algumas pistas para entender o funcionamento do presidencialismo em outros contextos. Por que teve êxito o presidencialismo nos EUA, e quais são as lições do caso norte-americano para a América Latina?

Para começar, quero ajudar a memória. Por que se criou nos EUA o sistema presidencial, sistema caracterizado pela separação de poderes, onde a função do poder Legislativo consiste em controlar o Executivo e vice-versa (o sistema de "freios e contrapesos")? Para além das influências doutrinárias importantes, entre elas o trabalho de Montesquieu e de Locke, existem dois fatores histórico-conjunturais da maior importância a serem considerados. Em primeiro lugar existe a enorme preocupação dos constituintes norte-americanos com a tirania, do executivo por um lado, de um parlamento controlado pela plebe pelo outro. Era tal a repulsa do governo de Jorge III, que os norteamericanos consideravam autoritário e absolutista, que procurouse idealizar um sistema para controlar o Executivo e despojá-lo do poder. É irônico pensar hoje que o sistema presidencial caracteriza-se por um Executivo forte e o parlamentarismo por um Executivo fraco, quando a realidade política do fim do século XVIII, como a de hoje, nos mostram outro quadro.

Apesar de que se acredita o contrário, o Executivo num sistema parlamentar é geralmente mais forte e tem maior capacidade de execução que o Executivo num sistema presidencial. $O$ presidencialismo é um sistema idealizado deliberadamente para ter um Executivo fraco. Ao mesmo tempo os constituintes de Filadélfia não queriam uma assembléia popular com muito poder, que temiam pudesse prejudicar as classes abastadas. Daí a insistência num Senado eleito não pelo povo mas pelas assembléias legislativas dos Estados, um corpo capaz de controlar os excessos da democracia - das maiorias, portanto.

$O$ segundo fator que pesa enormente na formulação da Constituição de 1789 é um fator político. A constituição norteamericana é um documento muito sui generis porque foi produto de muitos acordos e ajustes entre Estados relativamente autônomos, ciosos de seus interesses e soberania. O Senado foi criado para dar representação equitativa aos Estados, porque os Estados pequenos temiam a influência dos mais populosos e não aceitavam a noção de "um homem um voto" como norma final. $O$ 
Senado não representaria e sim os governos estaduais, enquanto a Câmara de representantes seria mais genuinamente representativa da vontade popular. E, como se sabe, as atribuições do governo federal eram muito limitadas, reservando-se os Estados uma grande parcela de poder. O centro de gravidade política localizava-se nas capitais estaduais e não em Washington, pelo menos até a segunda guerra mundial.

É importante constatar que nunca os constituintes de Filadélfia pensaram em ter um Executivo eleito diretamente pelo povo. A proposição de um delegado nesse sentido foi amplamente recusada. Os delegados à Convenção de Filadélfia viam na fórmula de eleição direta um perigo para a estabilidade democrática, ao criar um Executivo que apelaria diretamente às massas, tentando criar um poder pessoal e demagógico. George Mason disse que "seria tão contrário à natureza atribuir ao povo a escolha do perfil adequado do Chefe de Estado, como submeter um cego a um exame de cores."

Ironicamente, a proposta com maior apoio foi aquela da eleição do presidente diretamente pelo Parlamento. Esta fórmula foi votada favoravelmente cinco vezes, a última vez por uma votação de sete Estados a quatro. Afirmo que é irônico que se pensou na eleição do Executivo pelo parlamento porque, se tivesse sido aplicado aquele sistema, os EUA teriam evoluído para um sistema parlamentar, ou pelo menos semiparlamentar. O que aconteceu, entretanto, é que os pequenos Estados opuseram-se à fórmula da eleição pelo Parlamento, por temor ao maior peso dos grandes Estados na Câmara dos Deputados. Com muita urgência e pouco estudo sobre as possíveis conseqüências do sistema, chegou-se a um compromisso pelo qual o presidente seria eleito por um colégio de eleitores, eleitos por sua vez em cada Estado, e que, por sua condição de pessoas instruídas, escolheriam também um presidente ilustrado. Como se previu a possibilidade de que nenhum candidato obtivesse maioria, a Constituição estipula que a decisão final recaíria sobre a Câmara dos Deputados, onde cada delegação estadual teria direito a um voto.

Por que teve geralmente muito êxito o sistema de separação dos poderes nos EUA? Muitos são os fatores que podem ser enumerados. No meu entendimento, alguns são fatores contribuintes, que possibilitaram a consolidação e o funcionamento do sistema. Existe porém um fator que é mais que contribuinte - um 
fator necessário e suficiente. Primeiro quero referir-me aos fatores contribuintes.

1 - O primeiro é o Federalismo. O sistema norteamericano funciona relativamente bem porque tem esferas muito importantes da atividade pública nas mãos dos Estados e mesmo dos governos locais. Os orçamentos destes organismos excedem hoje os orçamentos do governo central e estão crescendo com velocidade maior. Isso contribui para diminuir a pressão sobre o governo central no sentido de dar solução para tudo e para impedir importantes conflitos em outros níveis políticos. Se acrescentamos a isso o fato de que nos EUA sempre existiu uma esfera do mundo não-governamental muito importante - o mundo da empresa e da iniciativa privada - o peso do Estado e portanto as responsabilidades do Estado têm sido menores. Nesse sentido e nas palavras de Garreton, existe uma grande autonomia do mundo civil com relação ao político.

2 - O segundo fator é a arbitragem da Corte Suprema, encarnada na doutrina da revisão constitucional, que, começando com a famosa decisão de Marbury versus Madison, estabeleceu o precedente de que a Corte Suprema pode declarar inconstitucional uma lei aprovada pelo Congresso e pelo presidente. É certo que a Corte Suprema dos EUA não se apartou fundamentalmente das maiorias legislativas. Contudo, nos momentos conjunturais e de crises, o prestígio da Corte permitiu que atuasse como árbitro nos conflitos entre os poderes do Estado e do governo central e os governos estaduais. Essa tradição, segundo muitos especialistas, tem sido a chave para o funcionamento do sistema de separação de poderes. É uma tradição que se ajusta também à tradição legal do direito comum nos EUA, e que teria sido difícil visualizar num sistema judicial baseado em códigos civis. O peso simbólico da Corte Suprema tem sido tal que mesmo Roosevelt no momento de seu apogeu político, com ampla maioria nas Câmaras, não pôde conseguir apoio para ampliar o número de cargos na Corte. Isso contrasta fortemente com a recente experiência argentina, onde Menem facilmente conseguiu uma Corte de seu agrado.

3 - O Controle dos militares pelo poder civil. Até a segunda guerra mundial existiu nos EUA uma forte resistência à noção de um poder militar profissionalizado. Desde o princípio valorizou-se muito a concepção do cidadão em armas, que teve sua expressão nas milícias estaduais, constituídas por cidadãos comuns que ofereciam parte do seu tempo para o treinamento 
militar. Os guardas nacionais, dispersos e descentralizados, manejados com critérios mais políticos que militares, permitiram uma forte supremacia civil sobre o mundo militar, evitando sua intromissão no mundo civil. É verdade que no século XIX os EUA tiveram um exército profissional forte no Sul, mas esse exército foi derrotado, impedindo que surgissem forças armadas propriamente profissionais até depois da Segunda Guerra Mundial.

4 - Por último, os EUA caracterizam-se por um sistema bipartidário não polarizado, nos termos de Sartori. Apesar de existirem diferenças importantes entre os partidos norte-americanos de um ponto de vista doutrinário, essas diferenças são mínimas quando observamos o espectro político da maioria dos países europeus e de muitos países latino-americanos. Nos EUA, os partidos sempre foram mais instrumentais e descentralizados, sempre foram grandes coalizões de partidos estaduais e locais, cujas forças mais importantes estavam sempre no nível local, onde existiam os conchavos e as patronagens políticas. É no nível local que está a influência importante para a ação diária da política, e onde está o dinheiro. O caráter de homogeneidade ideológica permite uma maior flexibilidade da política, que nunca passa a ser uma luta entre grandes utopias em pugna.

São esses, portanto, os fatores contribuintes mais importantes, que ajudam a explicar o funcionamento eficiente do sistema presidencial norte-americano. Mas afirmei que existe um fator necessário - um fator fundamental, sem o qual o sistema de dupla soberania, de separação de poderes, não teria prosperado. Esse fator está intimamente relacionado ao bipartidarismo e é muito simples: nos EUA, o bipartidarismo permitiu a criação de governos de maioria, ou seja, governos onde o executivo desfrutava de uma maioria do seu próprio partido no Congresso.

É um fato curioso os constituintes de Filadélfia não terem previsto a importância dos partidos na democracia, e mais, tinham um preconceito muito grande contra esses partidos, por considerá-los facções mesquinhas que atentariam contra os interesses superiores do Estado ou das Nações. Mas pouco tempo depois, o próprio Madison passou a caracterizar os partidos como a "fonte natural da liberdade", sem os quais a democracia não poderia existir.

A importância dos partidos tem sido tal que existe um consenso na ciência política norte-americana segundo o qual o fator fundamental que permitiu o satisfatório funcionamento do 
presidencialismo nesse país foi o papel de ligação entre os poderes do Estado, entre o Presidente e o Parlamento, realizado pelos partidos.

No começo do século, Woodrow Wilson comentou que "As diversas partes do governo estão unificadas num propósito comum, porque estão sob uma direção comum e constituem em si maquinarias para o controle dos partidos... Não se pode obter um governo satisfatório a partir de antagonismos."

Uma das eminências da ciência política norte-americana, V. O. Key, acrescenta: "Para que o governo funcione, as obstruções naturais da estrutura governamental devem ser superadas, e é o partido que, através de expedientes extra-constitucionais, cumpre este fim." Sundquist agrega: "O partido político foi a instituição que unificou os poderes separados do governo e aportou coerência ao processo de formulação de políticas públicas."

É óbvio, portanto, que para que o partido servisse de ligação entre o Executivo e o Congresso, facilitando a criação de governos eficientes, era necessário que o presidente tivesse maioria no Congresso. O dado fundamental para entender o sistema político norte-americano é que efetivamente assim aconteceu ao longo de sua história o governo norte-americano tem sido preferencialmente um governo de maioria, onde o partido do presidente teve maioria em ambas as casas do Congresso.

Se remontarmos à eleição de Andrew Jackson, quando se criam os partidos de massa nos EUA, ou seja, ao ano de 1928, vemos que todos os presidentes até Eisenhower chegaram ao poder com maiorias do seu partido no Congresso, com exceção apenas de Zachary Taylor em 1948, Rutherford Hayes em 1876, James Garfield em 1880 e Grover Cleveland em 1884. De vez em quando a oposição obtinha maioria numa casa do Congresso na eleição parlamentar realizada entre as eleições presidenciais, dando dois anos a um presidente com um congresso de oposição, mas isto não era comum. Entre 1897 e 1954, ou seja, toda a primeira metade do século XX, quando os EUA passam de uma sociedade rural e provincial para uma potência industrial e militar, o país teve um governo dividido somente por 8 anos, e só na segunda metade do período presidencial, quando o presidente já tinha afirmado sua autoridade.

Aos governos de maioria devemos acrescentar um fator adicional muito importante, que permitiu aos presidentes conservarem sua influência e conferiu coerência aos seus governos: a 
possibilidade de reeleição do presidente. Como o anteciparam muito bem os constituintes de Filadélfia, isso permitiu que os mandatários conservassem a liderança de seus próprios partidos, cujas sortes estavam ligadas às ambições políticas do líder. Do contrário, mesmo com um governo de maioria o presidente perceberia que estava perdendo poder no seu próprio partido, ao aproximar-se a eleição do seu sucessor. Apesar de não ser proibido, foi só com Roosevelt que um presidente postulou mais de duas vezes a reeleição à primeira magistratura. Isso conduziu, em 1951, à emenda proibindo a reeleição por mais de uma vez o que claramente diminuiu o poder do presidente.

Fica entretanto a pergunta: o que acontece agora, quando nos EUA não existe governo de maioria? Com efeito, desde 1956, o governo dividido passou a ser a norma em dois terços do tempo. No meu entendimento e no de muitos especialistas norte-americanos, este fato levou a uma crise institucional muito profunda nos EUA, crise que não é percebida como tal pela opinião pública desse país. Nos EUA existe uma reação visceral contra explicações de tipo sistemático. Os jornalistas e o público em geral culpam a má qualidade dos presidentes e dos políticos em geral, que não possuem estatura intelectual e não sabem governar. Afirma-se que somente têm em mente seus interesses particulares, em detrimento dos interesses gerais da nação. A verdade é que com um governo dividido, onde o presidente não tem maioria no Parlamento, é extremamente difícil governar, e é possível que essa frustração tenha levado a um desencanto com a carreira política.

O governo dividido constitui um fator importante para compreender o que provocou uma grave paralisia governamental nos EUA. As crises de Watergate, do Irangate, o problema catastrófico do déficit fiscal, a incapacidade de dar respostas viáveis à deterioração da competitividade dos EUA num mundo que se transforma, as incoerências na política exterior, são todos produtos em maior ou menor escala de um problema sério de falta de governabilidade, produto de governos de minoria - de governos divididos. Um governo que não funciona bem, que não é eficiente, perde também prestígio. As pesquisas mostram que o norte-americano médio perdeu muita confiança em seus governos e em seus partidos. Uma manifestação dramática dessa situação é a baixíssima participação eleitoral. Lembremos que em 1980 Reagan foi eleito por pouco mais de $20 \%$ dos eleitores habilitados. 
Sundquist resume o problema desta forma:

"Para ter políticas coerentes e em tempo hábil, afinal para que o governo funcione com eficácia conforme a teoria estabelecida, o presidente, o Senado e a Câmara têm que estruturar acordos. Quando o mesmo partido controla os três centros do poder, a capacidade de chegar a esses acordos é possível apesar das inevitáveis rivalidades e ciúmes institucionais... Mas num governo dividido, não são somente os distintos poderes do Estado que devem superar suas rivalidades estruturais, é preciso também superar os conflitos partidários... E isso é um processo difícil e árduo, caracterizado por conflito, demora e indecisão, levando freqüentemente a um impasse, a políticas ineficazes ou à falta de políticas... Num governo dividido, a disputa sadia converte-se numa disputa desleal e destrutiva entre os poderes do Estado como tais. Nessas circunstâncias, o presidente e o Congresso estão motivados somente para tentar derrotar e desprestigiar o outro... Ninguém deveria culpar os presidentes num governo dividido. O sistema é o culpado."

Apesar dessas dificuldades, porém, é evidente que os EUA podem sobreviver num governo dividido em grande parte pelos fatores contribuintes já apontados. Um governo dividido pode continuar num sistema federal, com uma enorme economia, com uma importante autonomia do civil, com instituições importantes como a Corte Suprema na arbitragem, e com partidos relativamente homogêneos e pouco estruturados que compartilham no fundamental uma mesma concepção da sociedade. Este último ponto é importante. Como demonstrou Reagan, o presidente tem a capacidade de apelar a deputados e senadores que não estão sujeitos a uma disciplina de partido para recriar coalizões temporárias, apesar das dificuldades desse jogo político. E, como aponta Sartori, também impera o pequeno jogo da política de "pork barrell", do clientelismo.

Por analogia, o que nos ensina a experiência norte-americana para a América Latina? É evidente que os pontos chaves que permitiram o funcionamento do sistema norte-americano apresentam-se de outra forma na América Latina.

Nossos países são centralizados - posto que o Estado passou a exercer um papel preponderante na atividade nacional. O Brasil é provavelmente a mais importante exceção a essa generalização. Em países como a Colômbia, as lutas pelo poder e pe- 
los cofres do Estado conduziram a freqüentes guerras civis entre os partidos.

Na América Latina, propriamente, não existiu uma tradição importante de tribunais constitucionais com prestígio para intervir eficazmente nos conflitos entre os poderes do Estado. Tampouco, com algumas notáveis exceções como o caso do Chile, não existiu um forte controle dos militares pelo poder civil. (No Chile, assim como nos EUA, o controle sobre os militares se fez com as milícias, tanto no século XIX como nos anos 30).

Seguindo a lógica do nosso argumento, porém, o ponto chave é que na América Latina foi muito difícil estruturar governos viáveis de maioria, em países onde existem importantes diferenças de fundo entre partidos e facções de partido e onde os Executivos foram privados da possibilidade de reeleição. A América Latina será o continente dos caudilhos, porém não na democracia, visto que o sistema presidencial tem gerado líderes fracos cujos governos atolaram-se numa paralisia contínua, produtos de fortes impasses entre os que detêm a soberania popular do lado presidencial e os opositores no Parlamento, igualmente zelosos de suas prerrogativas. $\mathrm{Na}$ maioria dos países latino-americanos um sistema bipartidário estável, onde um partido do presidente pudesse chegar a controlar ambas as casas do Legislativo, é muito difícil.

Pelo contrário, os sistemas partidários latino-americanos, em lugar de resolver as dificuldades postas pelo sistema da divisão de poderes, os agravam. Os partidos políticos na América Latina são o produto de uma tradição política muito diferente da norte-americana, onde as lutas ideológicas em torno dos grandes temas como o da Igreja e do Estado e do capital versus a classe trabalhadora marcaram a vida nacional.

No Chile, para dar um exemplo, as crises do presidencialismo quebraram o sistema no século XIX e novamente no século XX. A guerra civil de 1891 é um testemunho eloqüente da incapacidade de resolver a luta entre o Executivo e o Parlamento. O período posterior à guerra civil - a dita república parlamentar - foi também um sintoma do fracasso do presidencialismo. Não é verdade que se tenha estabelecido um sistema parlamentar no Chile como resultado da crise do presidencialismo. O que aconteceu é que, na luta permanente entre o presidente e o Congresso, o presidente e a presidência deram-se por vencidos e o Parla- 
mento passou a dominar a política, levando a um governo corrupto e anárquico. Mas o sistema continuou sendo presidencial, e os fracassos desse sistema podem ser atribuídos também ao sistema da divisão de poderes. No Chile chegava-se ao absurdo de que o presidente tinha que constituir seu ministério preocupado com obter apoio em ambas as câmaras.

Existe um grande mito no Chile, segundo o qual a constituição de 1925 , ao reestabelecer a autoridade do presidente no sistema da divisão de poderes, fortalece o sistema institucional. A constituição dos anos 20 não ajuda a solucionar o problema de fundo. O período de 1925 até 73 não é um período de um presidencialismo forte e eficaz, à diferença no período de 30 anos após à Guerra Civil.

É um fato fundamental que todos os presidentes chilenos, especialmente os que se apresentaram como candidatos independentes, acima da política e dos partidos, descobriram que governar o país era uma tarefa extraordinariamente difícil e frustrante. Isto porque os presidentes, num sistema partidário competitivo e polarizado, eram eleitos por minorias ou por coalizões maioritárias, que se desintegravam depois da eleição presidencial. Os presidentes nunca tiveram maiorias estáveis no parlamento, chocando-se continuamente com os problemas que apresentei a respeito dos EUA, com o agravante de partidos ideológicos, e de um sistema multipartidário que dificultava em demasia a estruturação de políticas coerentes. Nos países com sistema de partidos competitivos e polarizados agrava-se mais a polarização política e a distância ideológica sob um regime presidencial, porque num ambiente polarizado uma eleição presidencial ao invés de moderar a política a radicaliza.

Deve-se isso ao fato de que os setores mais extremistas podem ter um peso muito importante numa coalizão préeleitoral, muito além da quantidade de votos que podem trazer, especialmente se a competição é muito disputada. E aqui manifesta-se o problema do segundo turno. Para assegurar-se o triunfo, os dois candidatos com primeiras maiorias relativas no primeiro turno deverão comprometer-se com os setores mais extremistas.

Não obstante, o ambiente de crise constante do sistema político não é somente produto de uma radicalização dos discursos inspirados pelas eleições presidenciais. O dado mais importante é que no Chile e nos países vizinhos os presidentes nunca puderam contar com maioria parlamentar e suas coalizões 
presidenciais começavam a desintegrar-se pouco depois da eleição, porque não existiam incentivos políticos fortes para mantêlas. Por ser um sistema presidencial, o governo não depende da persistência da coalizão eleitoral para sobreviver.

Ademais, porque o presidente tem um período fixo não pode ser reeleito, e não pode ameaçar o Parlamento com sua dissolução; os dirigentes de outros partidos percebem imediatamente que a melhor forma de aumentar sua participação nas eleições municipais e parlamentares posteriores consiste em desligar-se das dificuldades de governar uma sociedade abalada por sérios problemas sócio-econômicos. As eleições posteriores caracterizam-se por uma política de melhor oferta, posto que a sorte dos governos não depende de uma votação perdida no Parlamento. Este passa a ser um centro de críticas ao Executivo, o qual, além disso, corre o risco de perder o apoio de seus próprios partidários, que se preparam para a próxima eleição presidencial.

A erosão das coalizões pré-eleitorais e a necessidade de ter apoio no congresso para programas de governo levam inevitavelmente os presidentes a procurar estruturar novas alianças temporárias. Isto significa ajustar o Ministério de acordo com estas alianças, processo complicado porque é necessário apoio majoritário em ambas as câmaras. Por isso, o sistema presidencial na América Latina tem sido sempre semi-parlamentar em maior ou menor grau, porque o mandatário é forçado a estruturar um ministério com dirigentes oposicionistas para obter apoio parlamentar.

No Chile, com exceção das presidências de Eduardo Frei e Jorge Alessandri, desde o ano de 1932 até 1973 os ministros mantiveram-se em cargos numa média inferior a 12 meses. $\mathrm{Na}$ presidência de Juan Antonio Rios a média foi de 6 meses, na de Salvador Allende, 7 meses.

$\mathrm{Na}$ maioria dos países latino-americanos a reação dos titulares do Executivo ante a impossibilidade de estruturar coalizões majoritárias para governar consiste em apelar diretamente ao povo, uma forma de populismo que privilegia a posição especial do presidente como representante legítimo da nação sobre os interesses particulares. A realidade de um período presidencial fixo, de um momento histórico muito curto para deixar um vestígio na história, leva todos os presidentes a passar por cima das oposições de facções no Parlamento, fazendo uso dos consideráveis recursos do Executivo com finalidades políticas e pedindo 
mais atribuições - com o ilusório propósito de criar, a partir do Executivo e em seis anos, uma maioria política que pudesse permitir ao partido governante seguir usufruindo do poder por um tempo mais longo.

Esta ânsia de impor soluções a partir do Executivo só contribui para uma tensão maior com os partidos de oposição representados no parlamento e para uma imagem de crise permanente na política. Não é por acaso que vários presidentes latino-americanos, incluindo alguns que considerávamos poderosos, suicidaram-se ou abandonaram voluntariamente seu cargo antes de terminar seu período constitucional.

Paradoxalmente, a reação ao impasse do presidencialismo da América Latina tem ajudado a incrementar os poderes do presidente. Mas esse esforço somente agrava o problema, ao reduzir as instâncias de negociações entre o presidente e o poder legislativo e os incentivos no parlamento para criar coalizões governantes. Entretanto, quanto mais forte o poder do mandatário, mais se desestimula a estruturação de um respaldo eficaz entre partidos e grupos ciosos de sua autonomia e de suas perspectivas eleitorais futuras. Poder-se-ia até sustentar que na América Latina existiu uma relação inversa entre o poder da presidência e o êxito do regime presidencial. Quanto mais forte tem sido o presidente, mais fraco e confrontante o regime presidencial.

A experiência recente da América Latina demonstra até que ponto um país pode ficar paralisado quando as maiorias políticas já abandonaram um governo fracassado, mas este governo perdura. Tanto Alfonsín como Siles Suazo tiveram que deixar a cadeira presidencial antes do término de seus períodos constitucionais por sua incapacidade de governar - apesar do enorme poder que a presidência tinha no papel. Existem outros presidentes fracassados que não deixaram o poder voluntariamente antes do término de seus períodos constitucionais, com nefastas conseqüências para seus países. Peliso, por exemplo, no recente caso do Peru. O presidencialismo, nos contextos multipartidários ou de forte crise, prende o país numa opção sem saída por um tempo muito longo.

A solução para esse impasse não pode ser uma mudança na natureza do sistema de fartidos políticos. Vimos como governos militares tão diferentes como os do Uruguai e do Chile procuraram criar um sistema de partidos políticos do tipo norteamericano, fracassando totalmente nesse objetivo. A literatura 
acadêmica das ciências políticas chegou à conclusão que não se pode mudar a fisionomia básica de um sistema de partidos políticos fortemente arraigados numa sociedade com a simples mudança nas leis de partidos e nas leis eleitorais. Os partidos simplesmente adaptam-se à lei até ter a oportunidade de mudá-la. É também evidente que os sistemas partidários duram muito mais que as mudanças econômicas que experimenta uma sociedade. No Brasil, onde os partidos são menos coerentes e arraigados, o governo militar também fracassou no seu propósito de criar um sistema bipartidário de caráter moderado. E o sistema presidencial deixa de incentivar hoje a institucionalização de um sistema de partidos políticos mais fortes e coerentes.

O problema, portanto, reside em como obter uma democracia estável a partir do reconhecimento da realidade política de nossos países. O lógico para países com sistema de partidos fragmentados ou multipartidários, onde um presidente não pode contar com a possibilidade de criar maiorias estáveis para governar, é passar para um sistema parlamentar. Não de assembléia, como aquele da Terceira ou da Quarta República francesas - mas com as características dos sistemas do mundo contemporâneo, com importantes garantias como o voto de desconfiança construtivo*.

Simplificando, na América Latina o sistema parlamentar teria três vantagens claras:

1. Em primeiro lugar, a geração de um governo parlamentar afrouxaria a enorme pressão existente num sistema presidencial, para estruturar coalizões amplas em torno de uma opção presidencial de valor zero, alternativa que estimula a polarização e pode enrijecer e mesmo radicalizar as opções. $O$ sistema do segundo turno, ainda que possa reduzir a incerteza que provém da eleição de um candidato com apoio minoritário, tem o efeito de exarcebar a polarização política, ao forçar a criação de coalizões de caráter temporário no calor de um conflito eleitoral. Um regime parlamentar, eleito com um sistema eleitoral de caráter proporcional com distritos relativamente pequenos, baixaria o perfil das eleições presidenciais e daria esperanças a

Sobre este ponto, ver o texto de Ruth Zimmerling, sobre a Alemanha, neste número. 
setores diferentes de poder participar da geração de coalizões governamentais.

2. Em segundo lugar: o funcionamento de um sistema parlamentar contribuíria para moderar a política. Isto é percebido muito claramente no caso do Chile. Tendo em vista as semelhanças nas posições dos partidos de esquerda e a Democracia Cristã em 1970, é provável que uma coalizão entre centro e esquerda teria subsistido, se o regime fosse parlamentar, já que Allende e seus colaboradores saberiam que as mudanças não poderiam ser muito drásticas, sob pena de provocar a queda do governo.

Com um sistema parlamentar os governos deveriam estruturar-se no Parlamento, privilegiando as opções de centro e de coalizões de partidos. Num regime parlamentar, os incentivos para criar coalizões de maioria são altos, posto que a falta de consenso majoritário leva a um novo processo eleitoral, com o risco para os partidos e os parlamentares de perder seus assentos.

Um sistema parlamentar teria o efeito de mudar a relação de forças dentro dos partidos, dando mais importância aos parlamentares eleitos e menos importância às cúpulas partidárias. Levaria também a uma maior disciplina de partido. E ainda mais, os membros proeminentes do Parlamento, ao ocupar cargos ministeriais, comprometer-se-iam com a gestão governamental.

Não é lógico argumentar que um sistema parlamentar não funcionaria bem num país como o Brasil, por falta de maturidade dos partidos. Os partidos e as direções políticas se ajustam aos incentivos que recebem do jogo político. Se o jogo político tem tendências centrípetas e não centrífugas, os elementos mais favoráveis ao diálogo irão consolidar-se dentro dos agrupamentos políticos. A disciplina partidária é uma variável dependente, não independente. A América Latina requer um sistema institucional que se ajuste à idiossincrasia do continente, profundamente marcado por suas tradições políticas e legais, mas também um sistema que desenvolva as tendências centrípetas; instâncias de consenso e compromisso político que podem gerar maioria para governar, dando garantias às minorias de que não serão destruídas. 
3. Em terceiro lugar, o funcionamento de um regime parlamentar eliminaria a paralisia governamental e o confronto entre o Executivo e o Legislativo, produto da falta de apoio majoritário ao presidente no Parlamento. Ter-se-ia assim um governo mais eficiente e ágil para solucionar os problemas do país. A nação não teria que viver com a rigidez de um compromisso por um período presidencial de seis ou oito anos, que já não conta com maioria operacional. O dramático caso de países latino-americanos, onde presidentes que no começo gozavam de grande popularidade perderam o poder real ao perder seu apoio parlamentar e tiveram que se demitir antes do tempo, demonstra o perigo de um mandato presidencial minoritário que se prolonga sem regras claras, apenas para completar o período constitucional. Por definição, um primeiro-ministro e seu gabinete tem mais poder que um presidente e o seu - até perder o apoio majoritário no parlamento, - quando então gera-se em pouco tempo uma solução para o impasse político.

Num momento histórico como o atual, quando existe um compromisso universal para fortalecer a democracia como o único sistema viável para uma sociedade moderna, é fundamental estudar a fundo as diversas opções institucionais do mundo contemporâneo, num esforço para dar aos países do continente um futuro democrático estável com um governo eficaz, que possa proporcionar desenvolvimento econômico com justiça social. A América Latina deve estabelecer um diálogo não apenas com seu passado, mas também com seu futuro - e olhar para as experiências felizes de outros países com os quais temos afinidades. Por que não podemos aspirar a ser como a Bélgica ou a Suécia ou a Áustria ou o Canadá? Seria irônico que num momento fundacional os países da América Latina, cujas idiossincrasias são muito mais parecidas com os países do velho continente, optassem por manter o sistema presidencial inventado em Filadélfia no final do século XVIII e não pensassem seriamente nas fórmulas políticas que se desenvolveram na Europa, fórmulas que funcionam muito bem em democracias tão novas como a Alemanha e a Espanha.

ARTURO VAlenzuela é Professor Titular de Ciências Políticas e Diretor do Centro de Estudos Latino-Americanos da Georgetown University, Washington, D. C. 20007. Telefone 202-298-2092; Fax 202-338-0608. 